\title{
Key criteria for information quality in the use of online social media for emergency management in New Zealand
}

MMIM592

By

Gunilla Elleholm Jensen

300192375

Supervisor: Dr Jocelyn Cranefield

Submitted to the School of Information Management,

Victoria University of Wellington

in partial fulfilment of the requirements for the degree of

Master of Information Management

October 2012 


\section{Executive summary}

Knowledge and information give people the power to make decisions and to act; they are the key to the success of real-time decision making. Social media can be valuable in emergencies where information can be shared to save lives and minimise the human and social impact. Fostering information quality is important in order to validate the information collected for decision making. With the empowerment of the general public and the abundance of information on social media, information quality becomes central to achieving an effective and efficient outcome in emergency response and saving lives.

A gap exists in the research in the area of information quality in the use of online social media for emergency management in New Zealand. The research question for this study is: What are the key criteria for fostering information quality in the use of online social media for emergency management in New Zealand? How are they achieved?

The data collection method employed was in-depth interviews of members of emergency management organisations in New Zealand. The interviews were followed by participant check.

Previous research has identified accuracy, consistency and relevancy as the most frequently acknowledged criteria for information quality. This study found that the three key criteria for information quality in the use of online social media for emergency management in New Zealand are:

- Using verified and validated information;

- Using timely information;

- Building and using networks.

There were two conflicts between the criteria: The need to dispel rumours or get time critical information out to the public can be in conflict with making sure that information is verified and trustworthy. The other conflict lies in the desire to control communication on social media, which hinders sharing of information and engagement with the public.

It was found that the key criteria for information quality can be achieved by engaging with followers, so that their shared information can be included in the EOCs standard verification processes, and at the same time letting the followers know what the time frame is for new information releases. 


\section{Preface}

This report is not confidential.

The author wishes to acknowledge the following people for their support:

1. My partner, flatmate, family, friends and colleagues for their help, understanding and encouragement.

2. Dr Jocelyn Cranefield for her excellent supervision.

3. The interview participants, for their time, advice and feedback.

I certify that the report is my own work and all references are accurately reported.

Gunilla Elleholm Jensen 


\section{Table of content}

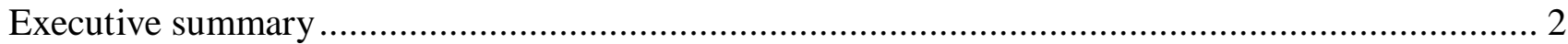

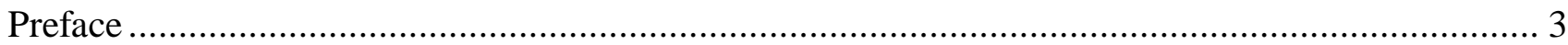

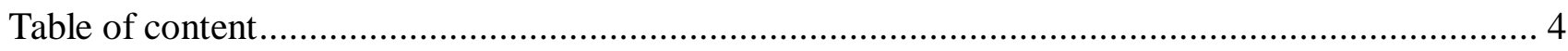

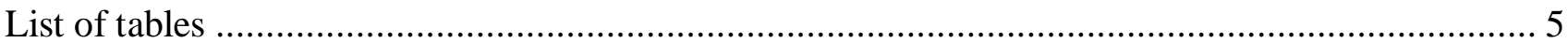

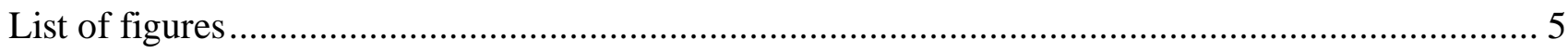

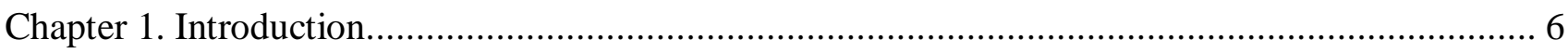

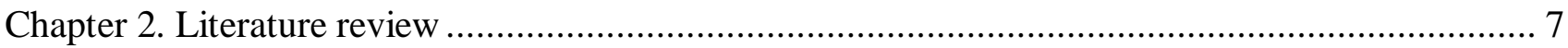

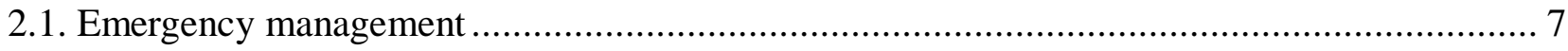

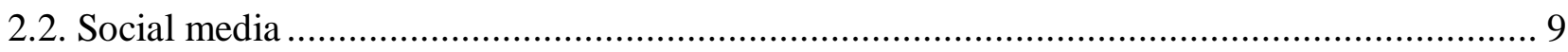

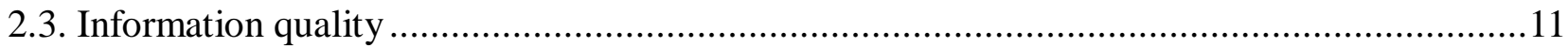

2.4. Information quality in social media use in emergency management in New Zealand............ 15

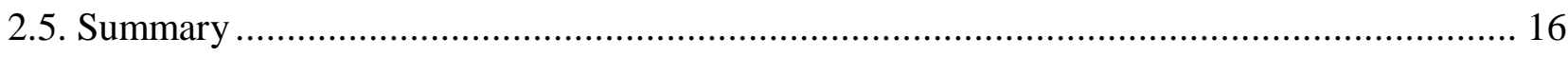

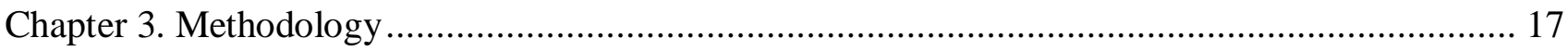

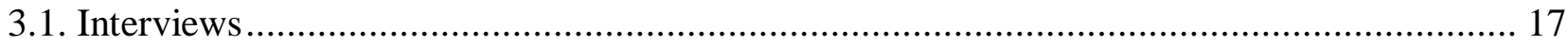

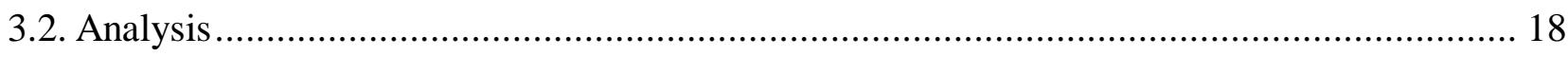

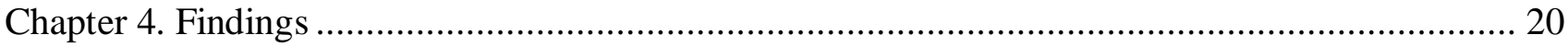

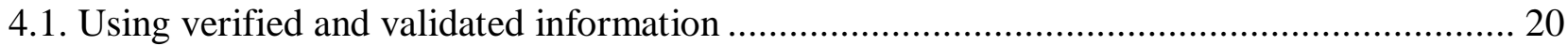

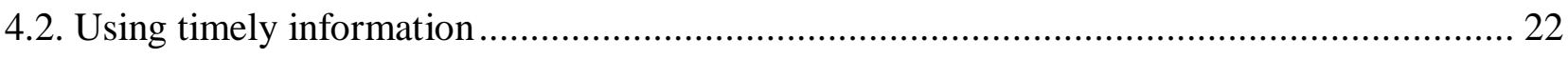

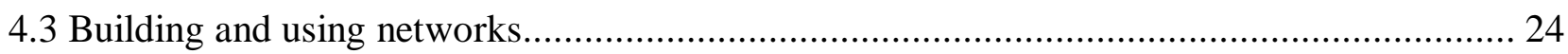

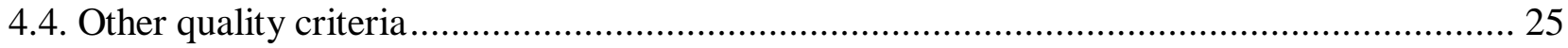

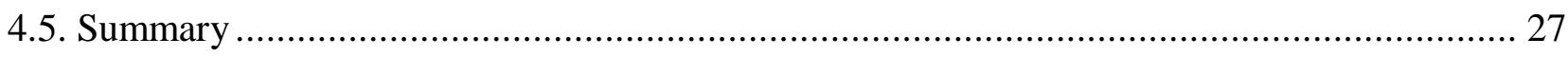

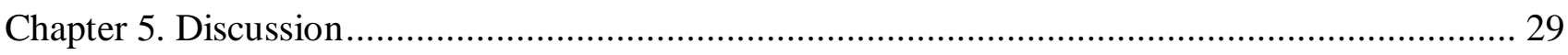

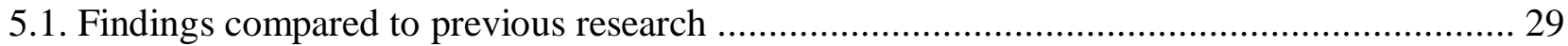

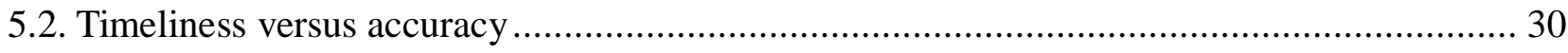

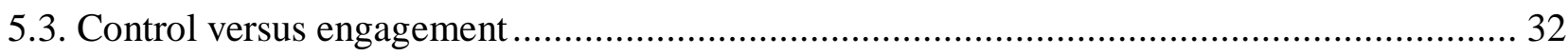

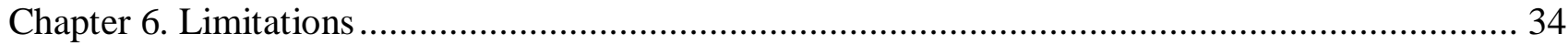

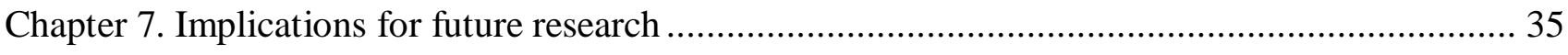

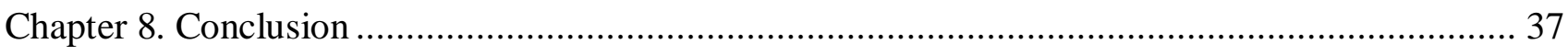

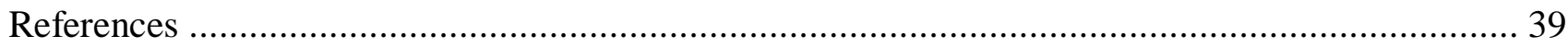

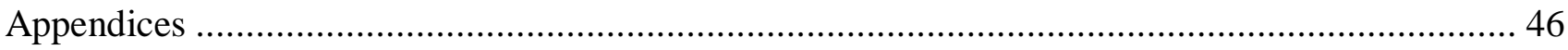




\section{List of tables}

Table 1: Information Quality Criteria

Table 2: Information Quality Criteria Type and Definitions

Table 3: How to Achieve Information Quality

\section{List of figures}

Figure 1: Force Field Analysis of Issuing a Tsunami Warning 


\section{Chapter 1. Introduction}

There is a growing interest in social media. One of the reasons is because of its rapid success in attracting participants:

"It took 38 years for the radio to attract 50 million listeners, and 13 years for television to gain the attention of 50 million viewers. The Internet took only four years to attract 50 million participants, and Facebook reached 50 million participants in only one-and-a-half years" (Nair, 2011).

There have been claims that social media is valuable for businesses, the medical society and in education (Miller, Marks \& DeCoulode, 2011; Dabner, 2012; Popoiu, Grosseck \& Holotescu, 2012; Dyer, 2012). Another area for investigation of social media's value is where information needs to be shared on social media to save lives, for example during an emergency.

Emergencies present challenges for managing information on social media. Emergency response can present a completely unique situation that traditional systems are not optimally configured to support. Kuehn (2011) emphasises that there is a need to ensure quality and reliability, in order to validate the information collected for decision making. With the empowerment of the general public and the abundance of information on social media, information quality becomes central to achieving an effective and efficient outcome in emergency response and saving lives.

New Zealand is located on the Pacific Ring of Fire, which makes the country prone to earthquakes, tsunamis, volcanic eruptions and other severe disasters. New Zealand's geography makes it naturally prone to floods, landslides and avalanches (Te Ara, 2012). As a small nation with a technical infrastructure that is in the process of being improved for the 4.3 million inhabitants (Ministry of Economic Development, 2012), it is a unique area with unique challenges. New Zealand is therefore an ideal place to investigate the quality of information on social media.

On the basis of these considerations, the research question for this study is: What are the key criteria for fostering information quality in the use of online social media for emergency management in New Zealand? How are they achieved? 


\section{Chapter 2. Literature review}

To answer the research question, it is critical to find out what is known about information quality in emergency management and identify gaps in previous literature. Before going into detail about information quality, an introduction is provided to emergency management and social media. The focus then shifts to information quality and what previous research agrees are the criteria for quality. Finally, this literature review finishes with a review of what has already been written about information quality in social media use in emergency management in New Zealand and what gaps exist in the current literature.

\subsection{Emergency management}

Emergency management has ancient roots. Early hieroglyphics show how cavemen dealt with disasters and the Bible speaks of many serious disasters. There are records of individuals and communities dealing with disasters, but the first organised attempts to manage these events mainly by governments, were recorded in the 1950s (Haddow \& Bullock, 2006).

Haddow \& Bullock (2006) define emergency management very broadly as "the discipline dealing with risk and risk avoidance". In New Zealand civil defence emergency management is defined in the Civil Defence Emergency Management Act 2002, where it

a) "means the application of knowledge, measures, and practices that-

(i) are necessary or desirable for the safety of the public or property; and

(ii) are designed to guard against, prevent, reduce, or overcome any hazard or harm or

loss that may be associated with any emergency; and

(b) includes, without limitation, the planning, organisation, co-ordination, and implementation of those measures, knowledge, and practices."

In this definition knowledge is central in emergency management, and knowledge is needed throughout the process for example to make decisions about an emergency. However, Kruke \& Olsen (2012) conclude that emergency management can be described as decision-making under uncertainty. This could be because of the uncertainty about the quality of information on which the knowledge is based, and that is why it is important to know the key determinants for its quality. 
Communication of quality information is critical in emergency management. "When a disaster occurs, the rapid gathering and sharing of crucial information among public safety agencies, emergency response units, and the public can save lives and reduce the scope of the problem" says Kuehn et al. (2011). Emergency management audiences can include general public, disaster victims, all levels of government, business community, media, elected officials, community officials, first responders, NGOs, law enforcement, medical communities, scientific communities, volunteer groups and others (Haddow \& Bullock, 2006).

Overlapping responsibilities and unclear reporting lines make communication among responders crucial. Communicating in the midst of an emergency response and recovery effort can be difficult because of conflicting reports, confusion and expectations of the public. Haddow \& Bullocks (2006) recognise that communication is the Achilles heel of disaster management, because of the number of involved parties. The cost of poor communication and coordination can be high and increase human loss (Haddow \& Bullock, 2006).

Decision makers face a number of challenges during an emergency (Day, Junglas, \& Silva, 2009; Nunamaker, Weber, \& Chen, 1989; Sniezek, Wilkins, Wadlington, \& Baumann, 2002). These are:

- information overload;

- the availability of fewer communication channels;

- data inaccessibility;

- data inconsistency;

- inadequate streams of information;

- low information priority;

- $\quad$ source identification difficulty;

- $\quad$ storage media misalignment;

- unreliability;

- omitting, delaying, and filtering of information; and

- processing of incorrect information during the emergency by intermediate message-handling units.

A number of these challenges are around information quality e.g. inconsistency, unreliability and Page 8 of 49 
incorrectness and it can be deduced from this list, that fostering information quality is important for decision makers.

Managing information flows is critical in an emergency because decision making is bounded by time urgency, and information may become outdated as the conditions change (Majchrzak et al., 2007; Hale, 1997). During a major disaster there are a large number of responders and agencies involved and the structural complexity of the response network is therefore very high (Xia et al., 2011). Updated emergency information must be allowed to flow vertically and horizontally among responders in a rapid manner (Hale, Dulek, \& Hale, 2005).

Seneviratne, Baldry \& Pathirage (2010) identify eight key knowledge success factors that will enable successful disaster management. Some of these major categories are environmental, legal, economic and political factors. However, their major categories are at a very high level and are not immediately applicable to information quality of social media in emergency management, so further research is needed in this area.

\subsection{Social media}

Social media networking sites belong to the social software category of knowledge management systems. Typical examples of social media are blogs, wikis and, of course, networking through the social sites of the moment such as Facebook, Twitter, LinkedIn or Google+. These tools, technologies and services have evolved into "social media" as a generic term characterised by providing a large range of Web 2.0 platforms and applications for conversational interaction between people or groups regardless of the distance (Avram, 2006; Raman \& Jennex, 2010; Popoiu, Grosseck \& Holotescu, 2012).

With tools such as online social media there are new communication and information channels that have the potential to ensure timeliness of information delivered from multiple sources, avoidance of information overload and establishment of accountability (Leidner et al., 2009; Pan, Pan \& Leidner, 2012). The public can even develop their own methods of informing others during disasters, when it is unable to get what it deems as reliable, timely information from the central responding agencies. Turoff et al. (2009, p. 379) also point out that "online forums have allowed people to transcend geographical distances that normally constrain the reach of helping efforts, to share information and 
coordinate citizen-led efforts."

Social media can function as "information aid" or psychological first aid because people feel connected to others, encouraged by help given, and hopeful for the future. Taylor et al. (2012) discuss how timely information exchange and promotion of connectedness, are able to act as sources of psychological first aid during a disaster and assist in supporting aspects of community resilience.

Mobile technology can enable better access to and exchange of information among disaster responders, agencies and the affected public. Access to real-time information can save lives. Furthermore, the information can be in many different forms, for example photos and video, and can be integrated to provide responders with a better understanding of the situation and the scale of the disaster (Kuehn et al., 2011).

With the empowerment of the general public and the abundance of information on social media, fostering information quality is central for decision makers to achieve an effective and efficient outcome in the emergency response.

There are a number of examples of social media being used during emergencies in New Zealand. A couple of examples are the Canterbury University's response to inform educational design with Facebook after the Canterbury Earthquake, where Facebook enabled on-going dialogue and information sharing between the institution's staff and the wider educational community (Dabner, 2012). Another example is Sam Johnson's famous UC Student Volunteer Army where up to 10,000 students helped Christchurch people deal with the aftermath of the Canterbury Earthquake (MacManus, 2011). There are also practical examples of low quality information communicated during the Canterbury Earthquake: An accompanying photo to an online posting about the damaged Christchurch Cathedral was of a different church or, when a well-meaning member of the public asked for urgent blood donations; this placed undue pressure on the Blood Service which was well stocked (Parker, 2011)

Despite being focused on New Zealand in this study, there are numerous examples overseas: The 2010 Haiti Earthquake was the first time the US government agencies employed social media and collaborative workspaces as the main knowledge sharing mechanisms (Yates \& Paquette, 2011). The 
use of social media during the 2010-2011 Queensland floods was hailed as a world leading effort (QPS, 2011). However, the opposite occurs too, for example, in Burma the military government had taken control and was blacking out news media reporting on the 2008 Cyclone Nargis crisis. The use of blogs and social media sites for the independent gathering and dissemination of information began to take hold among the public, until it was restricted through reducing the internet speed (Pan, Pan \& Leidner, 2012).

Social media clearly has strengths and presents opportunities in emergency management, but there are also risks and challenges. Huang, Chan \& Hyder (2010) mention the following six challenges of using social media in emergencies:

1. Access to internet either because of geographical location or because of individuals' low information technology literacy.

2. Disasters can destroy the required technological infrastructure and interrupt services.

3. In time of crisis and chaos, accuracy can be compromised.

4. The scalability of the social networking sites to handle the workload.

5. Privacy concerns.

6. Social media will never be the only solution to disaster preparedness and relief.

Social media has the potential to save lives in an emergency, but it is not without risks and challenges. Social media used for emergency management and emergency response must satisfy requirements for high standards of "reliability, resiliency, security, and availability that guarantee access to sufficient capacity on a day-to-day and emergency basis" (Kuehn et al., 2011), and that is why fostering information quality on social media is so important.

Kuehn (2011) emphasises the need to ensure information quality and reliability, in order to validate the collected information for decision making. With the abundance of information on social media, this becomes central to achieving an effective and efficient outcome in emergency response.

\subsection{Information quality}

Zhang, Zhou \& Nunamaker Jr (2002) say that "knowledge gives people the power to make decisions and to act", and that it is the key to the success of real-time decision making. Knowledge assists 
decision-makers in doing their job faster and more cost effectively and also enables various groups to share and reuse different resources (Zhang, Zhou \& Nunamaker Jr, 2002). Information contributes to knowledge, because interpretation makes knowledge out of information (Davenport \& Prusak, 1998). Information is an important resource for knowledge, but its effective use will depend on its quality.

Data quality criteria in emergency management are identified as "accuracy, timeliness, consistency, completeness, relevancy and fitness for use" (Fisher and Kingma, 2001). However, data is not information, but structure and context make information out of data. Pierce, Kahn \& Melkas (2006) question whether high-quality data automatically leads to better information quality, because there are other criteria that dictate the quality process.

There is a gap in research of what criteria leads to improved information quality in emergency management. However, this researcher suggest that general criteria for information quality may be applicable to social media used for emergency management.

There is no agreed list in academia of what general criteria will result in high information quality. Searching for information quality criteria or factors in ProQuest, Science Direct and Google Scholar helped the researcher identify studies that presented concepts, attributes and criteria linked to information quality in different contexts. Reviewing these papers, ten academic papers from various disciplines were chosen based on relevance and applicability to social media in emergency management. Some assumptions and interpretations were needed, since no papers specifically were for social media in emergency management. These papers present information quality criteria in various social media applications, web applications or other knowledge management systems in social settings. The ten papers are 1. Agarwal \& Yilivasi (2012); 2. Rao and Osei-Bryson (2007); 3. Kargar, Azimzadeh \& Ramli (2008); 4. Yoo, Vonderembse \& Ragu-Nathan (2011); 5 Lee, Younghee, Ryu \& TaeHoon (2007); 6. Poston \& Speier (2005); 7. Aggestam, Backlund \& Persson (2010); 8. Eppler \& Muenzenmayer (2002); 9. Kahn, Strong \& Wang (2002); 10. Tongchuay \& Praneetpolgrang (2008). Between them, they proposed the following 37 criteria to improve information quality: 
Table 1: Information Quality Criteria

\begin{tabular}{|l|c|c|c|c|c|c|c|c|c|c|}
\hline Criteria & 1 & 2 & 3 & 4 & 5 & 6 & 7 & 8 & 9 & 10 \\
\hline Accessibility & $\mathrm{X}$ & & & & & & & & & \\
\hline Accuracy & $\mathrm{X}$ & $\mathrm{X}$ & $\mathrm{X}$ & $\mathrm{X}$ & $\mathrm{X}$ & & & $\mathrm{X}$ & & $\mathrm{X}$ \\
\hline Applicable & & & & & & & & $\mathrm{X}$ & & \\
\hline $\begin{array}{l}\text { Appropriate } \\
\text { amount }\end{array}$ & $\mathrm{X}$ & & & & & & & & $\mathrm{X}$ & \\
\hline Believability & $\mathrm{X}$ & & $\mathrm{X}$ & & & & & & & \\
\hline Clearness & & & & & & & & $\mathrm{X}$ & & \\
\hline Cohesiveness & & & $\mathrm{X}$ & & & & & & & \\
\hline Completeness & $\mathrm{X}$ & & $\mathrm{X}$ & & & & & & $\mathrm{X}$ & $\mathrm{X}$ \\
\hline Comprehensiveness & & & & & & & & $\mathrm{X}$ & & \\
\hline Conciseness & $\mathrm{X}$ & & & & & & & $\mathrm{X}$ & $\mathrm{X}$ & \\
\hline Consistency & $\mathrm{X}$ & $\mathrm{X}$ & & & & & & $\mathrm{X}$ & $\mathrm{X}$ & $\mathrm{X}$ \\
\hline Correctness & & & & & & & $\mathrm{X}$ & $\mathrm{X}$ & & \\
\hline Credibility & & & & & & $\mathrm{X}$ & & & & \\
\hline Currency & & $\mathrm{X}$ & & & & & & $\mathrm{X}$ & & \\
\hline Degree of context & & $\mathrm{X}$ & & & & & & & & \\
\hline Details & & $\mathrm{X}$ & & & & & & & & \\
\hline Ease of application & & & & $\mathrm{X}$ & & & & & & \\
\hline $\begin{array}{l}\text { Ease of } \\
\text { understanding }\end{array}$ & $\mathrm{X}$ & & & & & & & & & \\
\hline Importance & & $\mathrm{X}$ & & & & & & & & \\
\hline Informative & & & $\mathrm{X}$ & & & & & & & \\
\hline Interpretability & $\mathrm{X}$ & $\mathrm{X}$ & & & & & & & $\mathrm{X}$ & \\
\hline Manipulability & $\mathrm{X}$ & & & & & & & & & \\
\hline Objectivity & $\mathrm{X}$ & & $\mathrm{X}$ & & & & & & $\mathrm{X}$ & \\
\hline Presentation & & & $\mathrm{X}$ & & & & & & & \\
\hline Relevancy & $\mathrm{X}$ & & & $\mathrm{X}$ & $\mathrm{X}$ & & & & $\mathrm{X}$ & $\mathrm{X}$ \\
\hline Reliability & & & & $\mathrm{X}$ & $\mathrm{X}$ & & $\mathrm{X}$ & & & \\
\hline Representativeness & & & & & & & & & $\mathrm{X}$ & \\
\hline Reputation & $\mathrm{X}$ & & & & & & & & & \\
\hline Security & $\mathrm{X}$ & $\mathrm{X}$ & & & & & $\mathrm{X}$ & & & \\
\hline Sharing & & & & $\mathrm{X}$ & & & & & $\mathrm{X}$ \\
\hline Timeliness & & $\mathrm{X}$ & & & & & & & & \\
\hline Understandability & & & & & & & $\mathrm{X}$ & & & \\
\hline Usefulness & & $\mathrm{X}$ & & & & & & $\mathrm{X}$ & \\
\hline Validity & & & & $\mathrm{X}$ & & & & & \\
\hline Value-added & & & & & & & \\
\hline Volatility & & & & & & & & \\
\hline Worthy & & & & & & & & & \\
\hline
\end{tabular}

It is apparent from Table 1 that researchers do not agree on a single set of criteria that results in high quality. However, shaded criteria are most frequently acknowledged. Accuracy, consistency and relevancy are highlighted with dark grey, and they are the most frequently acknowledged criteria. 
Based on Wang \& Strong's (1996) data quality framework, the criteria fall into four types of quality:

1. Intrinsic characteristics, for example accuracy and consistency are intrinsic characteristics of information quality, because they are knowable only from the information's use.

2. Contextual characteristics, for example relevance and timeliness are contextual characteristics of information quality, because they are subjective to the preferences of the user and the context where it is used.

3. Representational characteristics, for example presentation and usability are representational for the information because they represent it.

4. Accessibility characteristics, for example access and security, because they reflect the availability of the information.

Information quality exists in the interplay between these characteristics, where high quality is achieved when the intrinsic characteristics are of high quality and the product is usable, accessible and fit for the user's purpose.

Researchers do not use the same definitions of the criteria in Table 1 and not all of the above papers define their criteria. Based on the definitions in the ten papers, this researcher proposes the following definitions of the nine most used criteria from Table 1 in Table 2:

Table 2: Information Quality Criteria Type and Definitions

\begin{tabular}{|l|l|l|}
\hline Criteria & \multicolumn{1}{|c|}{ Type } & \multicolumn{1}{c|}{ Definition } \\
\hline Accuracy & Intrinsic & Information is correct and verified. \\
\hline Completeness & Contextual & Information is presented in its fullness. \\
\hline Conciseness & Intrinsic & Information is brief and to the point. \\
\hline Consistency & Intrinsic & Information is consistent and reliable. \\
\hline Interpretability & Representational & Information is presented in a comprehensible manner \\
\hline Objectivity & Intrinsic & Information is impartial. \\
\hline Relevancy & Contextual & Information is useful for a particular task. \\
\hline Reliability & Intrinsic & Information is reliable and trustworthy. \\
\hline Timeliness & Contextual & Information is current for the user's tasks. \\
\hline
\end{tabular}


It appears from Table 1 that accuracy, consistency and relevancy are the three most frequently acknowledged criteria for information quality in a variety of contexts. The question is whether these criteria for quality also apply in the context of social media and emergencies. Are accuracy, consistency and relevancy the key criteria for information quality in the use of online social media for emergency management in New Zealand? Or are there other more important information criteria in a context where lives could depend on it?

\subsection{Information quality in social media use in emergency management in New Zealand}

Very little has been written in peer-reviewed academic journals in this area. One researcher, Mersham (2010), described a few of the issues that the New Zealand Ministry of Civil Defence and Emergency Management (MCDEM) faced three years ago: On 30 September 2009 an 8.0 magnitude earthquake struck Samoa and Tonga and a tsunami was threatening New Zealand. While social media and traditional media was depicting the potential threat to New Zealand, the MCDEM appeared to be uninformed and indecisive in its public communication. This situation lasted for a couple of hours while information was validated and organisational protocols were followed (Mersham, 2010).

As discussed above there is no agreed list of key criteria for fostering information quality in the use of online social media for emergency management. In New Zealand, the study of information quality in social media use in emergency management is therefore also a developing phenomenon and not yet sufficiently described in academic literature. There is a need for research to be conducted in the area of information quality in the use of online social media for emergency management in New Zealand.

The sub-question to the main research question is how is information quality achieved? No research suggests how information quality is achieved on social media used for emergency management in New Zealand. However, some research discuss how information quality is achieved in general on social media: Agichtein et al. (2008) use a series of textual and social characteristics in order to separate high quality content from the rest on Yahoo! Answers. Kane (2011) suggest content shaping and depth of top contributor experience as quality criteria of peer-produced information for Wiki collaboration. Figueiredo et al. (2012) conclude that different quality aspects may impact differently the effectiveness of different social media services. Therefore, it can be concluded that further research is necessary in emergency management to find if previous suggestions for information quality may be applicable for 
social media in New Zealand.

\subsection{Summary}

Previous literature agrees that social media has the potential to save lives in an emergency, but it is not without its challenges: With the empowerment of the general public and the abundance of information on social media, fostering information quality is central to decision makers achieving an effective and efficient outcome in the emergency response. However, there is no accepted list of key criteria for fostering information quality in the use of online social media for emergency management, and researchers do not even agree on what criteria results in high quality in other contexts.

No research suggests how information quality is achieved on social media used for emergency management in New Zealand, and further research is required to find if general suggestions for information quality may be applicable.

Based on this literature review, it is apparent there is a gap in the research in the area of information quality in the use of online social media for emergency management, especially in the New Zealand context. This study aim to fill part of this gap. 


\section{Chapter 3. Methodology}

This chapter describes the method used to study the key criteria for fostering information quality in the use of online social media for emergency management in New Zealand.

The concept of online social media use for emergency management in New Zealand is an emergent area of research, and is not yet sufficiently described in academic literature. An interpretive qualitative research project is considered appropriate in this case. Interpretive research is characterised by giving an understanding of meaning and intentions, and it is suited to situations where the primary motivation is to discover and explore people's experiences (Hennink, Hutter \& Bailey, 2011).

Qualitative methods were used for this research. They provide rich information for exploring a phenomenon that has not been sufficiently studied, allowing the researcher to gain a better understanding of the phenomena or to identify attitudes and influences. This research aimed to build an understanding of the current experiences with online social media use for emergency management in New Zealand.

The goal of qualitative study is not necessarily broad application to the masses, but rather a unique understanding of individuals' specific experience of a particular phenomenon. The method provided details about participants' personal use and experiences of social media, and what their views are on using it in emergency management.

\subsection{Interviews}

For this study the data collection method employed was in-depth interviews. The interviews were followed by participant checks through a feedback system in form of an online discussion blog. This improved the trustworthiness of the findings and established credibility (Lincoln \& Guba, 1985).

The participants for this research project were members of emergency management organisations in New Zealand, who either worked or formerly worked with social media. The number of people in New Zealand emergency management who work with social media is a very small population. This researcher estimated that six interview participants were needed. Patton (1990) recommended using a group of individuals for interviews that is relatively small and purposefully selected. The selected 
sample provided information rich-data for the research study.

To gain as wide a representation as possible, the six interview participants that were invited to participate were either specifically chosen because of the organisation they were working in, or the snowball technique was used, where individuals would recommend participants. It was ensured that there were representatives from both public and private sector organisations. As for the public emergency management organisations, the New Zealand government emergency management system is organised into local, regional and national emergency offices each with their own responsibilities. It was ensured that the participants from the public sector were from a range of local, regional and national emergency management organisations. Four participants were from the North Island and two from the South Island. Three participants had been involved in the social media response for the 2011 Canterbury Earthquake, and had experience using social media in a major disaster.

For the in-depth interviews, a simple interview guide was constructed: The interview began with questions about the respondent such as their title, their role and responsibilities in emergency management; these questions were intended to establish rapport and trust between the interviewer and participant. Eight open ended questions followed to discover which quality criteria were most important to the respondent and how it were achieved (see appendix I). The individual interviews took place during the period June - July 2012 and one in September 2012.

\subsection{Analysis}

This is an interpretive study in which the researcher analysed the interview data for people's experiences and opinions of important criteria for information quality of social media in emergency management using a combination of deductive and inductive thematic analysis. This is a rigorous approach to look at the fit with what is already known, as well as new ideas and themes that arise from the interpretivist approach (Myers, 2009; Hennink, Hutter \& Bailey, 2011).

The interview data was coded using mainly inductive reasoning, where codes were derived from the specific terms that interviewees were using. However, deductive reasoning was also used to some extent based on the information quality criteria in Table 1. The researcher was first and foremost concerned with the interview participants' use of terms to describe criteria for quality and less concerned with the terms used in previous literature and theories. The reason for this is that it was 
assumed that there was the potential that quality of information on social media would be different from other communication systems. However, it was also expected that some of the criteria used in previous literature would be confirmed.

The interview data was coded in an Excel spread sheet. Any sentences from the interviews that mentioned information quality criteria in any form were added to the spread sheet. Sentences that mentioned several quality criteria were added multiple times, so that each criterion could be identified separately. The result was a dataset with 252 sentences.

There were 41 names and criteria for information quality identified in the dataset. This required summarising and interpretation of some sentences to some extent. These 41 names and categories were then aggregated into 22 conceptual constructs again using inductive and deductive methods, where the researcher interpreted themes that arose purely from the interview data but at the same time looked for themes identified in the literature (see Table 1).

Despite the fact that this study was not quantitative, weights were added to the constructs based on the number of participants who mentioned the construct and whether it was highlighted during the interview as a critical criteria for quality. The reason for adding weighting to the data was so that key criteria could be identified from less important criteria.

Trustworthy conclusions were paramount for this research. The findings were confirmed through a feedback system for the participants in the form of a secure and confidential online discussion blog. Interview participants received a couple of prompts and five of the six participants provided feedback.

There are ethical issues because the New Zealand emergency management community is very small. The research was not anonymous, but it was confidential and informed consent was obtained through a signed consent form (see Appendices II and III). The risk of the participants being able to be recognised was managed through removing all reference that would identify individuals or organisations. Victoria University of Wellington's School of Information Management gave their ethical approval for this research. 


\section{Chapter 4. Findings}

This research aimed to find the key criteria for fostering information quality in the use of online social media for emergency management in New Zealand. In this chapter the findings of the interviews are reported.

The three key criteria for fostering information quality in the use of online social media for emergency management in New Zealand were found to be:

- Using verified and validated information;

- Using timely information;

- Building and using networks.

This can be achieved by engaging with followers, so that their shared information can be included in EOCs standard verification processes, and at the same time letting the followers know what the time frame is for new information releases.

This chapter will describe these three criteria, why they are important and go into details about how they are achieved. Finally this chapter will describe other criteria mentioned by the interview participants.

\subsection{Using verified and validated information}

The key criteria for information quality in the use of online social media for emergency management in New Zealand is to make sure that information is verified and validated. Information has to be able to be validated, for example, checked for accuracy, so it becomes verified information. Only verified information should be communicated when official information is posted through social media.

"The key for using social media in emergency management is to verify all information". Interview participant $\mathrm{C}$

"One of the biggest factors is that we can validate it, that's probably one of the biggest things." - Interview participant A 
This criteria is important because unverified and invalid communication in emergencies can risk the lives of those who potentially depend on it. Most participants highlighted this, but some also saw limitations of this factor, where important pieces of emergency information were not able to be verified at a point in time and were therefore not able to be communicated:

"We were not prohibited from tweeting it, but we made the decision [that] actually we wouldn't tweet that information because we had no way of verifying it [...] the moment we did that and it was wrong, the authority of everything we were saying was gone basically. " Interview participant B

The best way to achieve verified and validated information is through the Emergency Operations Centres (EOCs) structured, standard validation process. They have structured, standard processes for validating information, according to interview participants, where social media becomes part of that process and is one of the sources used to verify information. It is important that other sources confirm the information. Before the information is passed on to the EOC, the information may be analysed for importance by aggregating, curating, filtering and analysing it:

I aggregate the information, I collect the information, then I'll curate it, I'll filter it and analyse it to make sure it is important and it is going to be official to an EOC or an Incident Commander. - Interview participant $\mathrm{C}$

"Are there any other creditable sources of the information to confirm a report is true or out of date?" - Interview participant E

Another closely related aspect of this factor is the relevance of the information that is posted. It has to be useful, appropriate and valuable information. It goes both ways: Useful and valuable information from social media can be relayed on to the EOC, so that informed decisions can be made and useful and valuable information can be disseminated back to the public.

"Is it worth passing on this information to others or is it just noise? " - Interview participant E 
This is the key question according to one of the participants who tweeted during the Canterbury Earthquake response, and it assists the EOC use their standard validation processes. Passing on irrelevant information to the EOC could slow down their validation processes and the risk would be that critical time was wasted.

\subsection{Using timely information}

Timeliness is another important factor which has implications for quality of communication via social media. The pace of social media is much faster than other communication channels, such as media releases to the public during an emergency. On social media the response is instantaneous and timeliness is therefore important.

"Social media is a conversational space and it can be very fast paced, so I think that the other important factor is being able to respond within that timeframe” - Interview participant D

"Social media does almost need to streamline how you put out your official messages, so that media releases should go out every four hours or something. You can't really do that with social media, you need to go more quickly.” - Interview participant A

One of the strengths of social media like Twitter is that information is easily available on smart phones, and it can help ease the load on the Civil Defence website should it become congested.

The public want the information immediately, but this can be in conflict with the verification process, because information takes time to go through the EOC verification process. One participant used the example of a tsunami, where there is no information to release until a wave analysis has been done, and a decision is made whether or not there is a viable threat to New Zealand.

"The first behaviour is grab your cell phone, go to civildefence.govt.nz and what's the update? And they expect the update to be there right now, and that's where our channel lies in getting the events out there in a timely fashion and a tsunami is a classic example” - Interview participant $\mathrm{B}$ 
Timeliness involves keeping people up to date even when no official information has been released. The need to dispel rumours or get time critical information out to the public, could sometimes be in conflict with making sure that information is verified and trustworthy. This was reflected in the interviews:

\begin{abstract}
"We also found that it was hard to get information, so for example we knew about information that was coming out but we always had to wait until the media release had been written and signed off before we could actually put some information out on social media even though there was a demand for it." - Interview participant D

"We knew our information was correct and there were so many different pieces of information out there that people were talking about that they were concerned about it being very easy for things to be misunderstood or misinterpreted being official, whereas if it had gone through a complete sign off process despite having time implications it was known to be correct and accurate.” - Interview participant D
\end{abstract}

Various solutions to achieve timely information have been applied in cases given by participants, for example saying that they are waiting for the official information to be released, or clearly labelling unconfirmed information, for example, using the Twitter hash tag \#UNCONFIRMED:

"One of the things we've looked at is a labelling system of identifying what's unconfirmed, so that if we recognise that people want information, we may not be $100 \%$ sure of it, but we are still going to put it out, so you can make decisions based on that information, but recognising that it's unconfirmed." - Interview participant A

Another practical aspect of timeliness is the need to time or date-stamp time critical messages, so that people are able to apply common sense to re-tweeted messages or their RSS feeds. When a piece of information is no longer correct, it is important to close the loop on the message by communicating when a tsunami warning is cancelled, electricity is on again, or it is no longer necessary to boil water.

"If we run an announcement that says, such and such and such a suburb is being evacuated, ok, in three hours' time, when they are being let back in, make sure you put out a tweet message that 
says 'the evacuation completed, residents are moving back in', so you are closing that sort of, the chances that someone is going to see that older message, they'll still see that older message but chances are that they'll see more recent message and they get the full story." - Interview participant B

Active monitoring of information redistributed through social media is required according to one interview participant, so that out-of-date information can be closed down swiftly. Crowd sourcing of information on social media poses challenges and timeliness is critical so that for example incorrect rumours are dispelled.

"Crowd sourced information online really needs constant moderation and checking to make sure information that was once critical has a use-by date and metadata to allow users to make up their own mind about the validity or not of a post." - Interview participant E

Timeliness is an important information quality factor on social media because of the pace of communication. However, the conflict between the public's expectations and the EOC verification process has a number of implications for information quality. Solutions to these challenges have been to close the loop on messages and use the Twitter hash tag \#UNCONFIRMED.

\subsection{Building and using networks}

"[The] most important thing that people in New Zealand can do before that happens is build those relationships, so I'm able to literally call upon a network of digital support, emergency management practitioners throughout the world." - Interview participant C

Building relationships, networks and connections before an emergency is another important criteria for information quality, because it makes communicating and responding much faster, when relationships have already been established. Knowing which organisations or individuals post verified and trusted information on social media can only be done by following and monitoring them for a period of time. This knowledge is valuable, because it can, for example, be used when re-tweeting information from electricity companies on power outages. Another aspect is engaging with one's own followers and the community, answering questions, finding out what critical information people need and keeping up to 
date:

"It was simply because we had built up a fairly good set of connections so that we know what Twitter accounts are reputable and that we can trust and that we also know that people will want to know some of that information. [...] We've been following them and monitoring them for the last two years and the quality that they have put out has always been of use to the audience that they are targeting, the wider society, so it has been useful and it has been accurate and they have never put anything out that is questionable." - Interview participant D

Engaging with organisations and individuals before any potential emergency is simple on social media; there are no barriers in place other than those which are self-imposed regarding who one wants to have a closer relationship with by befriending and following.

Some participants commented that content had to be specific for social media. The traditional media release format is for example not useful for the 140 character Twitter format. Having a human voice and putting a bit of personality into the messages was also mentioned as a positive factor.

"We still keep our official tone for getting our key messages out there, but we can also be more human on those channels when responding to queries or asking for information or trying to find out what's going on in certain areas." - Interview participant D

"We deliberately injected a bit of Kiwi light-heartedness into some of our messages, so we'd say things like 'now is not the time for no. 8 wire, if you've got problems with electricity, get an electrician', 'be a sport, help your neighbours out'. " - Interview participant B

Engaging and building networks on social media is important, because of the benefits of the knowledge gained, and this is not difficult on a medium where following someone is one click away. However, communicating on social media is different, and imposing the traditional media release format will not be useful.

\subsection{Other quality criteria}

In addition to the three main identified criteria for information quality on social media, there were a Page 25 of 49 
number of other criteria mentioned by interview participants. These were mainly around the knowledge ability of the emergency management organisation's staff and how they could plan and use guidelines.

Pre-planning of messages, for example, for the 140 character Twitter format and using guidelines such as Greater Wellington's (2012) Social Media in an Emergency: A Best Practice Guide, was seen as valuable:

"We've certainly done some work around some set templates for that, which is not unusual in the sense that you have a set template for a media release in [NZ emergency management organisation] in an emergency event, why not have some templates for social media that needs to go live." - Interview participant D

One interview participant commented on the requirement of having staff who understand information and social media. The skill of being able to confidently interpret the information that they are receiving on social media, knowing the boundaries what can and cannot be shared on social media is a highly valuable set of skills. It relates to the third criteria around knowing and understanding your networks. Achieving this, requires regular training and exercises: After the Canterbury Earthquake a number of knowledge sharing activities were initiated. Formal training in social media is also happening in a number of emergency management organisations:

"They've also integrated some of their emergency training a component on social media so that those people who go and work inside an EOC, Emergency Operations Centre, have a greater awareness of how that channel works and how to include it in their planning and their thinking and their actions." - Interview participant D

Trained, knowledgeable staff who use social media confidently will improve information quality. Other issues that were commented on are privacy, where breaches of individuals' privacy in difficult situations can have negative consequences. The desire of top management to maintain control of a medium that is difficult if not impossible to control, hinders engagement with the public. Lack of resources was reflected upon as a weakness for effective and efficient communication through social media in an emergency. 


\subsection{Summary}

In this chapter key criteria for fostering information quality in the use of online social media for emergency management in New Zealand were identified. They are:

- Using verified and validated information;

- Using timely information;

- Building and using networks.

In addition to these three criteria other factors such as having trained, knowledgeable staff using social media and employing guidelines and prepared templates was also discussed.

Solutions on how to achieve the three criteria are summarised in Table 3:

Table 3: How to Achieve Information Quality

\begin{tabular}{|c|c|}
\hline Criteria & How to achieve it? \\
\hline $\begin{array}{l}\text { Using verified and validated } \\
\text { information }\end{array}$ & $\begin{array}{l}\text { - Aggregating, curating, filtering and analysing the information. } \\
\text { - Using the EOCs structured, standard validation process. }\end{array}$ \\
\hline Using timely information & $\begin{array}{l}\text { - Communicating while waiting for the official information to be } \\
\text { released. } \\
\text { - Labelling unconfirmed information. } \\
\text { - Time and date-stamping time critical messages. }\end{array}$ \\
\hline Building and using networks & - $\quad$ Through engaging and sharing information. \\
\hline
\end{tabular}

Engaging with followers will enable their shared information to be included in the EOCs standard verification processes, and at the same time letting the followers know what the time frame is for new information releases.

At the end of the interviews, the participants were asked to summarise the most important criteria. The following responses from the six participants support the findings of the three key criteria:

"One of the biggest factors is that we can validate it" - Interview participant A

Page 27 of 49 
"I think that's really important those two points namely timeliness and being willing to engage" Interview participant D

"What is important and critical when used in emergency management is that the information is responsibly shared. It's valuable to an EOC. It is verified information, it's proactive and it's unambiguous. " - Interview participant C

"Trust, validity, timeliness, relevancy. Without these, postings and tweets become noise or at worst actively hinder users wanting to be involved in conversations online during an emergency. " - Interview participant E

"Information has to be $100 \%$ correct, it will be scrutinised" - Interview participant F

"We acted as a relay service rather than a content generator service and that also gave the group a bit of comfort that we weren't going to give out the wrong information and potentially cause a panic or a concern, but that we'd also have a bit of credibility and trust behind the account, so we would say things like 'we don't have that information, we'll try and find out for you'. ' -

Information participant B 


\section{Chapter 5. Discussion}

In this chapter, there will first be a discussion of how the findings relate to previous literature and if there are any discrepancies; suggestions will be made to why these findings are different from other research. After this, the following two conflicts between quality criteria will be discussed: Timeliness versus accuracy and control versus engagement.

\subsection{Findings compared to previous research}

Accuracy, consistency and relevancy are in general the most important criteria for information quality. The question arose as to whether accuracy, consistency and relevancy are the key criteria for information quality in the use of online social media for emergency management in New Zealand; or as indicated by the findings, there are other more important factors?

This researcher suggests that the criteria accuracy is similar and can substitute for the criteria verified and validated information, so that coincides well with the literature and the findings of this study support this key criteria. This is not at all surprising in an emergency management situation, where lives may depend on having verified, accurate information.

Consistency was mentioned by a couple of participants as important, but not everyone mentioned this criteria and it was not deemed as being one of the key criteria in this context.

Relevance as an important criteria is supported in this research, and one participant mentioned it as one of the top factors, but relevant information has to be filtered from that which is irrelevant.

In a perfect world we would get very succinct, detailed information sent to us through Facebook quickly, that would be awesome, but in reality you get pieces of information from different people, from their slant or their feelings that usually have a huge emotional attachment you then have to try and decipher what is being said. - Interview participant A

There can be many reasons why consistency and relevancy are not among the three key criteria in this study. Social media presents an overload of information, with some being highly consistent and relevant, and other items completely irrelevant and impossible to use because of their emotional 
connotations. It is therefore necessary for the user to filter irrelevant information.

Social media is unique in terms of information management. Building networks is not a quality criteria for general information quality, where it may only be one-way communication; this is why the general literature does not mention this as an important criteria. However, social media is often two-way communication and building connections is the basis for social networking. It is therefore not surprising that this was one of the key quality criteria found in this research. In this area the findings are different from previous literature on information quality because the criteria is contextual.

Timeliness has been mentioned in Agarwal \& Yilivasi (2012); Lee, Younghee, Ryu \& TaeHoon (2007) and Tongchuay \& Praneetpolgrang (2008) as critical to information quality. In the case of social media in emergency management, most interview participants mentioned this as one of the top priorities because of the nature of this medium.

It is interesting to note, that none of the three key criteria are intrinsic characteristics of information quality as discussed in the literature review. Information quality on social media is mainly contextual and subjective to the preferences of the user which means it depends on location, time, emotions and other contextual factors. This is an interesting finding and this researcher calls for further research in this area.

In summary, previous literature is supported by the findings in this research. However, there are areas where the research findings are different from previous literature because unlike other communication tools, social media is a two-way communication tool and highly contextual. This discrepancy is not surprising, but it does indicate a need for more research in this area.

\subsection{Timeliness versus accuracy}

One key finding in this study was the tension between timeliness and the verification process. Demands from the public can be seemingly unreasonable and one participant felt as if social media participants were constantly shouting "I want the information and I want it now and I want it on my cell phone!" This suggests that the public's expectations of emergency responders in New Zealand are too high. Up to 80 per cent of those interviewed in an American Red Cross 2011 survey said they expected emergency responders to be actively monitoring social media for information from people 
affected by an emergency, and respond within one hour of a posting on social media requesting assistance (Chrichton, 2012). This is now the possibility in the United States through funding from the computer company Dell, for the American Red Cross to actively monitor social media and respond during major disasters (Red Cross, 2012). However, New Zealand does not have the resources to monitor all social media channels or provide such a rapid response, and there is a clear need to manage expectations and demands of the public.

As described in the findings, there is a conflict between timeliness and the verification process; the need to dispel rumours or get time critical information out to the public can sometimes be in conflict with making sure that information is verified and trustworthy. Figure 1 displays this tension using the example of a tsunami warning being issued. The time to make decisions and potentially evacuate is up against the EOC's verification process, where an accurate wave analysis is required and media releases and other communication needs to be signed-off. One practical way around this is by saying that information is being released and what the time frame is. Another option is to label it as unconfirmed information.

Figure 1: Force field analysis of issuing a tsunami warning

Timeliness
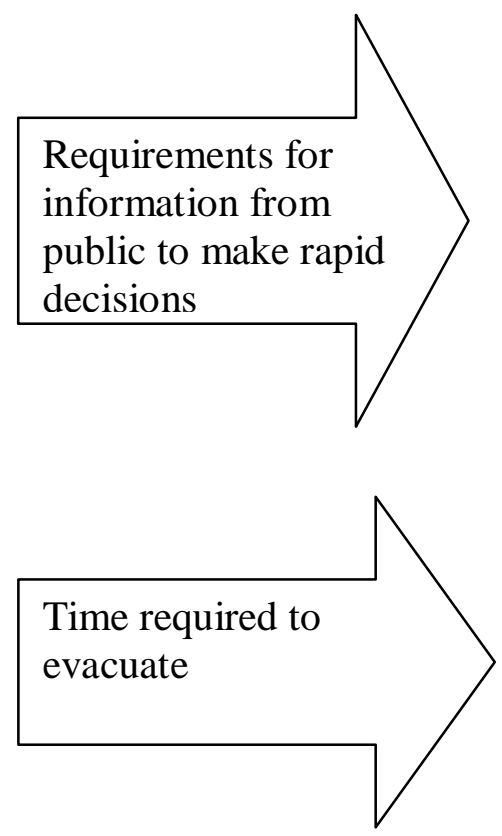

\section{Accuracy/verification process}
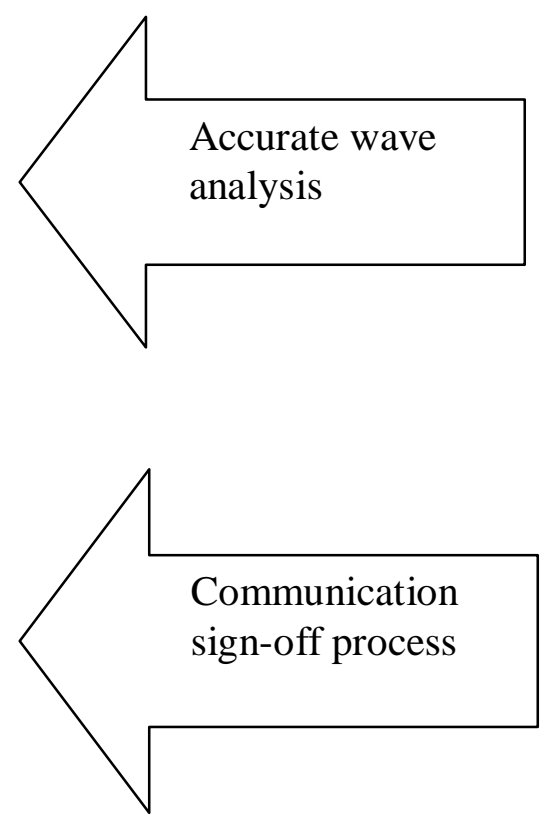
Information professionals have concluded that accuracy and timeliness are the most important attributes of good information assets (Oppenheim, Stenson \& Wilson, 2004). The conflict between accuracy and timeliness is known in other areas, for example journalism (Deuze \& Yeshua, 2001), where social media dramatically reduces the time between an event and public awareness, which creates a divide between the materialisation and journalistic reporting of an event. This is the distance created by the time required to discern, document, check and publish information against the connected individuals or citizen media where the information may only be partially based on facts. Speed and immediacy are in conflict with the journalistic ethics of accuracy, fairness, completeness and balance. A news story can be distributed worldwide in a few seconds and secure a "scoop" for the journalist, and if the story appears to be inaccurate, it can be replaced or be taken off-line immediately. This can be an attractive solution for journalists, but inaccuracy of emergency information can potentially have a deadly outcome.

Swindell \& Hertog (2012) found that journalists and official emergency management organisations have somewhat similar attitudes and beliefs about accuracy, timeliness and audience panic, but they vary widely with regard to their understanding of the other's views. Unfortunately their findings indicate that this divergence is a concern, because it could become a barrier to the provision of highquality emergency news to the public.

The topic of accuracy versus timeliness requires further research to confirm findings, investigate implications and risks and find potential ways to mitigate these. Research may provide further methods to resolve this tension.

\subsection{Control versus engagement}

Another conflicting issue that was raised in the findings, is the control of communication on social media versus engagement and sharing of information. An example of this is when information is available from other organisations on power cuts; because emergency organisations have been very protective of the messages that go out, simply because the situation could be a matter of life or death, they do not want to disseminate this through their communication channel. With social media the

Page 32 of 49 
landscape has changed for them. It has been said that social media is about community engagement, not about controlling public communication, and that some organisations have misunderstood the power of the medium (Stephens, 2012; Mersham, 2010). This issue was reflected in the interviews:

"It's really interesting hearing some of the higher people in [NZ emergency management organisation] talking about the desire to really control the information that is going out, which really limits how you can go about sharing other people's information. ”-Interview participant D

It was positive to hear from one interview participant that in the short period between the Canterbury earthquake in February 2011 and the June 2012 snowstorm in Christchurch, the communication on social media seemed to have changed significantly in this area:

Ifound that I was re-tweeting a lot more content that was pertinent to the emergency situation than I was in February. - Interview participant D

It could seem that New Zealand emergency management organisations have learned from the past. This is also reflected in the new Greater Wellington's Guidelines for Social Media in an Emergency (2012), which encourage engagement with the community and timely two-way information sharing during an emergency.

Following on from the issue around unnecessary control, is the desire to engage more with social media followers. The key, said one of the interview participants, was to

"Listen to our followers' concerns regarding the sharing of information especially after a major event and their down stream effects, and if we can we'll improve our communications messaging as well as furthering our engagement with online communities relevant to the [NZ emergency management organisation]” - Interview participant E

Instead of pushing out information, it was suggested that it may be more effective to listen to the public and discover who they are and what information they want from the emergency management organisation. This requires engagement with the public and not negative control over what information is disseminated. 


\section{Chapter 6. Limitations}

The limitations of this research are in the interpretive research method employed, the exclusion of stakeholder groups and the limited number of interview participants.

As this is interpretive research it is based on the views and opinions of the six interview participants. Other people may have different view or opinions about what the key criteria for information quality are.

It was estimated that six interview participants would provide a rich dataset to answer the research question. It can always be argued that further participants could have been included from other local and regional locations providing further data.

The main limitation of this study is that only emergency management officers were interviewed. If the users - the New Zealand public - or high level contributors, for example the Emergency Controller, had been included in this research, they may have focussed on other quality criteria. Given the resources available for this project, it was not possible to include further stakeholder groups. 


\section{Chapter 7. Implications for future research}

In this research there were a number of issues identified which require further research: Some criteria were found to be different from previous literature on information quality, and there was discovered to be some conflict between timeliness and accuracy, and control of communication on social media and engagement.

Building networks as a criteria for information quality is different from criteria identified by previous literature because unlike traditional media such as newspaper and radio, social media is a two-way communication tool. This difference is not surprising, but suggests that more research is needed.

Another area that requires more research is the topic of accuracy versus timeliness. This research highlights some of the implications and risks of this conflict, but further research is needed to confirm these and investigate if there are other implications and risks.

None of the three identified criteria are intrinsic characteristics of information quality as indicated in the literature review. These findings highlights that information quality on social media is mainly contextual and subjective to the preferences of the user. This is an interesting finding and this suggests a need for further research in this area.

The conflict between control of communication versus engagement requires further research. According to the findings of this study, it could seem that attitudes and communication on social media have already changed significantly in this area, but this will need to be investigated further to find what further implications and risks arise from this conflict.

It was suggested that it may be more effective to listen to the public and discover who they are and what information they want from the emergency management organisation. This requires engagement with the public and not negative control over what information is disseminated. However, risks are associated with less control over information. As New Zealand emergency management organisations release their staff to engage and re-tweet more information, it would be ideal to research what the implications and risks are. 
One issue that these findings have not gone into detail about is crowdsourcing. Crowdsourcing involves the broadcasting of a problem as an open call for solutions to an unknown group of solution givers. "The crowd" will submit solutions to the problem. The question is whether crowdsourcing of emergency information would resolve some of the conflicts, for example getting timely information out. Earthquake and wave data could be made available for example, and open for "the crowd" to analyse and reach conclusions regarding any tsunami possibility.

This study only focuses on social media and emergency management in New Zealand. Research into larger scale events is needed, because large scale disasters can have a worldwide impact, with implications for information quality on a global scale. 


\section{Chapter 8. Conclusion}

The research question for this study was: What are the key criteria for fostering information quality in the use of online social media for emergency management in New Zealand? How are they achieved?

Previous studies have agreed that social media has the potential to save lives in an emergency, but it is not without its challenges. With the empowerment of the general public and the abundance of information on social media, fostering information quality is central for decision makers in achieving an effective and efficient outcome in the emergency response. However, there is a gap in previous literature because there is no recognised list of key criteria for fostering information quality in the use of online social media for emergency management, and researchers do not even agree on what criteria results in high quality information in other contexts.

Previous research has identified accuracy, consistency and relevancy as the most frequently acknowledged criteria for information quality. It was found in this study that the three key criteria for information quality in the use of online social media for emergency management in New Zealand are:

- Using verified and validated information;

- Using timely information;

- Building and using networks.

Previous literature's criteria are supported by the findings in this research. However, the research findings are also different from previous literature because unlike other communication tools, social media is a two-way communication tool and highly contextual.

Achieving these information quality criteria involves the following solutions:

- Aggregating, curating, filtering and analysing the information.

- Using the EOCs structured, standard validation process.

- Communicating while waiting for the official information to be released.

- Labelling unconfirmed information.

- Time and date-stamping time critical messages.

- Building and using networks through engaging and sharing information. 
There were two main conflicts discovered between some of the quality criteria: The first conflict is between timeliness and the verification process. The need to dispel rumours or get time-critical information out to the public could sometimes be in conflict with making sure that information is verified and trustworthy. This tension is found in other areas such as journalism, where public awareness creates a divide between materialisation and the journalistic reporting of an event.

The other conflict is between the desire to control and protect information and communication on social media versus engaging and sharing of information. Communication on social media is changing as more community engagement is achieved in New Zealand. This results in better fostering of information quality on social media.

Using verified, validated and timely information and building and engaging with one's networks are the key criteria for fostering information quality in the use of online social media for emergency management in New Zealand. This can be achieved by engaging with followers, so that their shared information can be included in EOCs standard verification processes, and at the same time letting the followers know what the time frame is for new information releases. 


\section{References}

Agarwal, N. \& Yiliyasi, Y. (2010). Information quality challenges in social media. Retrieved 17 October 2012 on

http://mitiq.mit.edu/ICIQ/Documents/IQ\%20Conference\%202010/Papers/3A1_IQChallengesInSocial Media.pdf

Aggestam, L., Backlund, P. \& Persson, A. (2010). Supporting knowledge evaluation to increase quality in electronic knowledge repositories. International Journal of Knowledge Management, 6(1), 23-43

Agichtein, E. et al. (2008). Finding high-quality content in social media. WSDM Conference 2008, 183193.

Avram, G. (2006). At the crossroads of knowledge management and social software. Electronic Journal of Knowledge Management, 4(1), 1-10

Civil Defence Emergency Management Act 2002. Accessed on 4 September 2012 on http://www.legislation.govt.nz/act/public/2002/0033/latest/DLM149796.html?search=ts act\%40bill\%4 Oregulation\%40deemedreg_emergency_resel_25_h\&p=1

Dabner, N. (2012). 'Breaking Ground' in the use of social media: A case study of a university earthquake response to inform educational design with Facebook. Internet and Higher Education, 15, $69-78$

Davenport, T.H. and Prusak, L. (1998). Working Knowledge: How Organizations Manage What They Know, Harvard Business School Press, Boston.

Day, J., Junglas, I., \& Silva, L. (2009). Information flow impediments in disaster relief supply chains. Journal of the Association for Information Systems, 10(8), 637-660

Deuze, M. \& Yeshua, D. (2001). Online journalists face new ethical dilemmas: Lessons from the Netherlands. Journal of Mass Media Ethics: Exploring Questions of Media Morality, 16(4), 273-292 
Dyer, O. (2012). Patient who received liver after social media campaign reports success. British Medical Journal, 344 doi: 10.1136/bmj.e3538

Eppler, M. \& Muenzenmayer, P. (2002). Measuring information quality in the web context: A survey of state-of-the-art instruments and an application methodology. Proceedings of 7th International Conference on Information Quality, 187-196.

Figueiredo, F., et al. (2012). Assessing the quality of textual features in social media. Information Processing and Management, http://dx.doi.org/10.1016/j.ipm.2012.03.003

Fisher, C.W. and Kingma, B.R. (2001). Criticality of data quality as exemplified in two disasters. Information \& Management, 39(2), 109-116

Greater Wellington Regional Council (2012). The Social Media in an Emergency: A Best Practice Guide. Accessed 6 October 2012 at http://www.gw.govt.nz/social-media/

Haddow, G.D. \& Bullock, J.A. (2006). Introduction to emergency management. Elsevier ButterworthHeinemann, Burlington, MA.

Hale, J. (1997). A layered communication architecture for the support of crisis response. Journal of Management Information Systems, 14(1), 235-255.

Hale, J., Dulek, R., \& Hale, D. (2005). Crisis response communication challenges. Journal of Business Communication, 42(2), 112-134.

Hennink, M., Hutter, I. \& Bailey, A. (2011). Qualitative Research Methods. London, SAGE Publications.

Huang, C., Chan, E. \& Hyder, A.A. (2010). Web 2.0 and internet social networking: A new tool for disaster management? - Lessons from Taiwan. BMC Medical Informatics and Decision Making, 10(57). Accessed 1 September 2012 at http://www.biomedcentral.com/1472-6947/10/57 
Kahn, B.K., Strong, D.M. \& Wang, R.Y. (2002). Information quality benchmarks: Product and service performance. Communications of the ACM, 45(4), 184-192

Kane, G.C. (2011). A multimethod study of information quality in Wiki collaboration. ACM Transactions on Management Information Systems, 2(1), 4:1-4:16

Kargar, M.J., Azimzadeh, F. \& Ramli, A. R. (2008). An experimental framework for ranking qualty of information on weblog. International Conference on Information Quality (ICIQ-08), MIT,US, 29-43

Kruke, B.I. \& Olsen, O.E. (2012). Knowledge creation and reliable decision-making in complex emergencies. Disasters, 36(2), 212-232

Kuehn, A., Kaschewsky, M., Kappeler, A., Spichiger, A. \& Riedl, R. (2011). Interoperability and Information Brokers in Public Safety: An Approach toward Seamless Emergency Communications. Journal of Theoretical and Applied Electronic Commerce Research, 6(1), 43-60

Lee, J., Younghee, L., Ryu, Y. \& TaeHoon, K. (2007). Information Quality Drivers of KMS. IEEE Computer: International Conference on Convergence Information Technology, 1494 - 1499

Lincoln, Y. \& Guba, E.G. (1985). Naturalistic Inquiry, Sage Publications, Newbury Park, CA.

Lindell, M.K., Prater, C. \& Perry, R.W. (2007). Introduction to emergency management. John Wiley \& Sons, Hoboken, NJ

MacManus, R. (2011, February 27). \#EQNZ: Social Media response to Christchurch Earthquake. Accessed 2 August 2012 from http://www.readwriteweb.com/archives/eqnz_social_media_response_to_the_christchurch_ear.php

Majchrzak, A., Jarvenpaa, S., \& Hollingshead, A. (2007). Coordinating expertise among emergent groups responding to disasters. Organization Science, 18(1), 147-161

Mersham, G. M. (2010). Social media and public information management : The September 2009 
tsunami threat to New Zealand. Media International Australia, 137, 130- 143.

Miller, M., Marks, A., \& DeCoulode, M. (2011). Social Software for business performance: The missing link in social software: Measurable business performance improvements. Deloitte. Accessed 30 September 2012 at http://www.deloitte.com/view/en_US/us/Industries/technology/e9c1b39fb701e210VgnVCM3000001c5 $\underline{\text { 6f00aRCRD.htm }}$

Ministry of Economic Development (2012). Ultra-fast broadband initiative. Accessed on 2 September 2012 at http://www.med.govt.nz/sectors-industries/technology-communication/fast-broadband/ultrafast-broadband-initiative

Myers, M.D. (2009). Qualitative Research in Business \& Management. London: SAGE Publications.

Nair, M. (2011). Understanding and Measuring the Value of Social Media. Journal of Corporate Accounting \& Finance, 22(3), 45-51

Nunamaker, J., Jr., Weber, S., \& Chen, M. (1989). Organizational crisis management systems: planning for intelligent action. Journal of Management Information Systems, 5(4), 7-32.

Oppenheim, C., Stenson, J. \& Wilson, R. (2004). Studies on information as an asset III: views of information professionals. Journal of Information Science, 30(2), 181-190

Parker, S. (2011). Social media usage following the Christchurch earthquake. Accessed 2 September 2012 at http://stuartparker.wordpress.com/2011/02/

Patton M.Q. (1990). Qualitative Evaluation and Research Methods. Newburg Park: SAGE Publications.

Pierce, E., Kahn, B. \& Melkas, H. (2006). A comparison of quality issues for data, information, and knowledge, in: Khosrow-Pour, M. (Ed.), Emerging Trends and Challenges in Information Technology Management: Proceedings of the 2006 Information Resources Management Association Conference, 
17th IRMA International Conference, Washington, DC, USA.

Popoiu, M.C., Grosseck, G. \& Holotescu, C. (2012). What do We Know about the Use of Social Media in Medical Education? Procedia - Social and Behavioral Sciences, 46, 2262-2266

Poston, R.S. \& Speier, C. (2005). Effective use of knowledge management systems: A process model of content ratings and credibility in indicators. MIS Quarterly, 29(2), 221-244

QPS, (2011). Queensland Police Service Disaster Management and Social Media - a case study, accessed 2 August 2012 from

http://www.police.qld.gov.au/Resources/Internet/services/reportsPublications/documents/QPSSocialMe diaCaseStudy.pdf

Raman, M. \& Jennex, M. (2010). Knowledge management systems for emergency preparedness: The way forward. Journal of Information Technology Case and Application Research, 12(3), 1-11

Rao, L. and Osei-Bryson, K. (2007). Towards defining dimensions of knowledge systems quality. Expert Systems with Applications, 33(2), 368-378

Red Cross (2012). The American Red Cross and Dell Launch First-Of-Its-Kind Social Media Digital Operations Center for Humanitarian Relief. Accessed 13 May 2012 http://www.redcross.org/portal/site/en/menuitem.94aae335470e233f6cf911df43181aa0/?vgnextoid=1cc 17852264e5310VgnVCM10000089f0870aRCRD

Seneviratne, K., Baldry, D. \& Pathirage, C. (2010). Disaster knowledge factors in managing disasters successfully. International Journal of Strategic Property Management, 14(4), 376-390

Sniezek, J., Wilkins, D., Wadlington, P., \& Baumann. P. (2002). Training for crisis decision-making: psychological issues and computer-based solutions. Journal of Management Information Systems, 18(4), 147-168.

Stephens, K. (2012). Social Media are about Engagement, not Control. Accessed on 28 August 2012 
at http://idisaster.wordpress.com/2012/03/22/social-media-are-about-engagement-not-control/

Swindell, C. \& Hertog, J. (2012). Dimensions of Emergency Messages as Perceived By Journalists and Sources. Public Relations Journal, 6(1). Accessed on 1 September 2012 at http://www.prsa.org/Intelligence/PRJournal/Documents/2012SwindellHertog.pdf

Taylor, M. et al. (2012). The role of social media as psychological first aid as a support to community resilience building. The Australian Journal of Emergency Management, 27(1), 20-26

Te Ara (2012). Explore natural hazards and disasters. Accessed on 30 September 2012 at http://www.teara.govt.nz/en/natural-hazards-and-disasters

Tongchuay, C. \& Praneetpolgrang, P. (2008). Knowledge Quality and Quality Metrics in Knowledge Management Systems. Fifth International Conference on eLearning for Knowledge-Based Society. Accessed on 13 May 2012 http://elearningap.com/eLAP2008/Online/21_Fullpaper_Chawanrat\%20Tongchuay1_revised.pdf

Turoff, M., Van de Walle, B. \& Hiltz, S. (2009). Emergency Response Information Systems: Past, Present, and Future in B. Van de Walle., M, Turoff and S, Hiltz (Eds.) Information Systems for Emergency Management, New York, M. E. Sharpe, 369-387.

Wang, R. Y., \& Strong, D. M. (1996). Beyond accuracy: What data quality means to data consumers. Journal of Management Information Systems, 12(4), 5-34

Xia, W., Becerra-Fernandez, I., Gudi, A., \& Rocha, J. (2011). Emergency management task complexity and knowledge-sharing strategies. Cutter IT Journal, 24(1), 20-25

Yates, D. \& Paquette, S. (2011). Emergency knowledge management and social media technologies: A case study of the 2010 Haitian earthquake. International Journal of Information Management, 31, 6 13.

Yoo, D.K., Vonderembse, M.A. \& Ragu-Nathan, T.S. (2011). Knowledge quality: antecedents and Page 44 of 49 
consequence in project teams. Journal of Knowledge Management, 15(2), 329-343

Zhang, D., Zhou, L. \& Nunamaker Jr, J.F. (2002). A Knowledge Management Framework for the Support of Decision Making in Humanitarian Assistance/Disaster Relief. Knowledge and Information Systems, 4(3), 370-385 


\section{Appendices}

Appendix I: Survey questions

Appendix II: Interview information sheet

Appendix III: Consent form

Page 46 of 49 


\section{Appendix I}

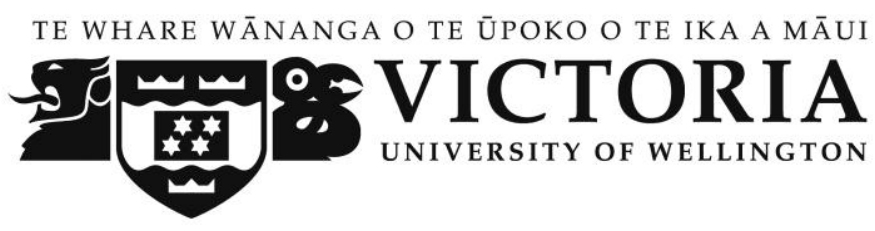

\section{Interview questions}

Project title: Critical factors for knowledge quality in the use of online social media for emergency management in New Zealand.

Researcher: Gunilla Jensen, Master of Information Management student, School of Information Management, Victoria University of Wellington.

- What is your work title and your role and responsibilities in emergency management?

- Can you describe your experience with social media in emergency management?

- What does knowledge quality (or information quality) on social media mean to you?

- How do you access and use emergency knowledge (or information) from other people on social media? How do you ensure it is of high quality? What makes someone a good contributor of emergency information on social media?

- Can you describe a time where you were concerned about the quality of information on social media about an emergency? What did you do about it?

- Can you describe what you did to ensure you provided high quality information about the Canterbury Earthquake through social media?

- What do you do today to provide high quality emergency information?

- What factors of knowledge quality in the use of social media for emergency management do you think are most important? Why?

In finishing:

1. Do you have anything else in mind you would like to add?

2. Do not hesitate to email me if you have any further thoughts on the subject being discussed.

3. The data from all the interviews will be collated and combined and you are given the opportunity to comment and rank the criteria using an polling tool between 16 July -5 August 2012. You will receive further instructions via email.

4. Thank you very much for your participation. Do not hesitate to contact my supervisor or myself if you have any further comment or questions. 


\section{Appendix II}

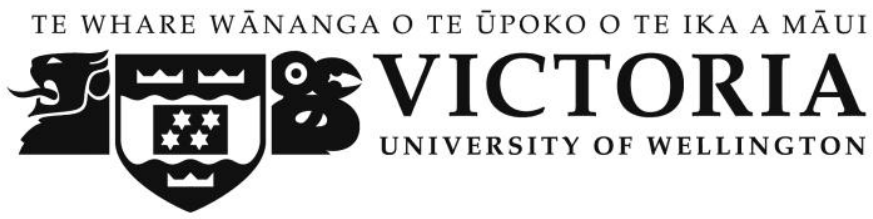

\section{Interview - information sheet}

Project title: Critical factors for knowledge quality in the use of online social media for emergency management in New Zealand.

Researcher: Gunilla Jensen, Master of Information Management student, School of Information Management, Victoria University of Wellington.

Dear ,

Thank you for your interest in participating in this research project which investigates the critical factors for knowledge quality in the use of online social media for emergency management in New Zealand. I am currently a Master of Information Management student at Victoria University of Wellington, New Zealand. This project is part of my Master Research Project.

Your participation in this research project will involve two steps: (1) an interview of approximately 60 minutes. The interview will be conducted between 11 June 2012 and 1 July 2012. The interview can be conducted either face-to-face if you are in Wellington, over the phone, or using an Internet video conferencing tool of your choice. The interview data will be digitally recorded. The data will be analysed to develop a provisional set of knowledge quality factors. Then (2) you will be invited to comment on these results in a secure, private and confidential online environment using an anonymous user name (e.g. User 1) and to rank the criteria using a polling tool. This will happen between 16 July 2012 and 5 August 2012.

The School of Information Management Human Ethics Committee has given ethical approval for this research. Your participation in this research project is voluntary. You may ask to have the information you provide through the interview to be withdrawn without question at any time before 9 July 2012.

Your name and the name of your organisation will be kept confidential and the results will be presented in an aggregated form which will prevent individuals to be identified. However, please be aware that it may be possible for some people who read the research results to infer your identity or the identity of your organisation, based on the comments you make or the experiences you report. Other participants in the online blog environment may be able to infer your identity based on the content of the discussion.

All data from the project will be held securely throughout the project (electronic data will be password protected and paper documents will be kept in a secure locked cabinet) and only available to myself and my supervisor. It will be destroyed two years after the conclusion of the study. The Research Project will be submitted for examination to the School of Information Management and deposited in the School and/or University Library. The research results may be presented at conferences, and one or more articles may be submitted for publication in scholarly journals.

If you have any questions or would like to receive further information about the project, please contact me or my supervisor, Dr Jocelyn Cranefield, at the School of Information Management at Victoria University, P.O Box 600, Wellington, phone +64 44636887 or Jocelyn.Cranefield@vuw.ac.nz

Regards,

Gunilla Jensen

phone: +6421066 2536

email: jensenguni@myvuw.ac.nz 


\section{Appendix III}

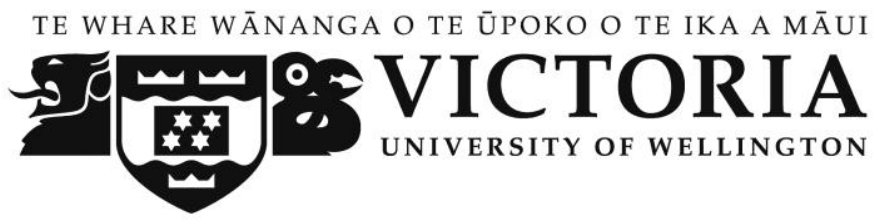

\section{Consent form}

Project title: Critical factors for knowledge quality in the use of online social media for emergency management in New Zealand

Researcher: Gunilla Jensen, Master of Information Management student, School of Information Management, Victoria University of Wellington.

Supervisor: Dr. Jocelyn Cranefield, School of Information Management, Victoria University of Wellington.

- I have been provided with adequate information relating to the nature and objectives of this research project, I have understood that information and have been given the opportunity to seek further clarification or explanations.

- I understand that the interview will be recorded and that the audio recordings and other information obtained will be destroyed two years after the conclusion of the project.

- I understand that I may withdraw from this study at any time before 20 August 2012 without providing reasons. I understand that if I withdraw from the project, any data I have provided will be destroyed.

- I understand that any information or opinions I provide will be kept confidential and reported only in an aggregated or non-attributable form.

- I understand that the results may be used in the researcher's Master Research Project, conference papers or journal articles.

- I agree to take part in this research.

Date Signature 